\title{
Research on the Fusion Development of Central Plains Traditional Culture and New Culture Industry
}

\author{
Yumeng Zhang \\ Henan University of Animal Husbandry and Economy, Zhengzhou, Henan, 450044
}

Keywords: fusion development; Central Plains’ traditional culture; new culture industry

\begin{abstract}
The integration of the traditional culture of the Central Plains and the emerging culture industry should make full use of the various digital technologies and software and hardware carriers in the emerging culture industry, so as to announce the profound contents; to mobilize all enthusiasm and enable the public to participate in the heritage of the Central Plains and carry forward their National cultural spirit; to find the entry point for new cultural industries, product culture, cultural products, and develop the cultural industry with the characteristics of the Central Plains.
\end{abstract}

\section{Introduction}

The term "Central Plains" is an ever-expanding concept in Chinese history. "Ci Yuan" gives the "Central Plains" a narrow and broad interpretation. The narrow Central Plains refers to this area of Henan. In the broad sense, the Central Plains refers to the middle and lower reaches of the Yellow River or the entire Yellow River Basin. Xu Guangchun once said: "The Central Plains is a relative regional concept with Henan as the main body. First, it refers to the big concept, including the middle and lower reaches of the Yellow River; the second is the concept of the Middle Yellow River; the third is a small concept, and refers only to Henan Province. The Central Plains referred to in this study are mainly limited to the narrow Central Plains - Henan Province. Henan is a big cultural province. Traditional culture of Henan has formed a traditional cultural industry with considerable scale and strength with its abundant resources. However, we must also realize that the development of Henan's cultural industry is still relatively backward, and some old cultural industries and industries the categories went into recession, and some new cultural formats and emerging cultural industries emerged. Under the background of the construction of the Central Plains Economic Zone, how to tap the positive factors in the traditional culture of the Central Plains and how to integrate the traditional culture of the Central Plains with the development of new cultural industries is a major research topic. The purpose of this study is to explore the possibilities and effective approaches for the integration of the traditional culture of the Central Plains with the emerging culture industry.

\section{Central Plains Traditional Culture}

Henan is a large province of traditional cultural resources. Its traditional cultural resources include important cultural heritages such as celebrity culture, ancient capital culture, tomb culture, root-seeking culture, Buddhist culture, food culture, opera culture, and martial arts culture. The Central Plains culture with Henan traditional culture as its main body is very broad and inclusive. At the same time, it also has the closedness of farming culture, and it also shows the root characteristics of the Central Plains culture. Since the reform and opening up, under the impact of the commodity economy and the mass media, Chinese society has undergone a profound transformation [1]. The Central Plains, with Henan as the representative, has also undergone an important transformation under this background. People have brought new things to the world. The new fashion is overwhelming. Many aspects of the traditional culture of the Central Plains have been forgotten in the no-man's corner. In recent years, from the government to the people, Henan has begun to pay attention to the development and utilization of traditional culture, to achieve a leap 
from a large cultural province to a strong cultural province in Henan, and to achieve the grand plan of the rise of Central China. Promote Henan's economic development, advance Henan's spiritual civilization construction, vigorously develop Henan's tourism industry, enhance the cultural content of Henan's tourism resources, build world-class brands, develop Central Plains urban agglomerations and enhance the competitiveness of the Central Plains cities, and enhance the attractiveness of the Central Plains urban agglomerations And competitiveness. Some people predict that the 21st century economy will be composed of two parts: culture and industry. Culture will surely become a new image of the economy. For Henan, the realization of the sustained and rapid economic development and the optimization and upgrading of the industrial structure require the advantages of a new type of cultural industry to optimize and integrate the traditional culture of the Central Plains and innovative development. Since 2006, the protection of "intangible cultural heritage" nationwide has become a focus of attention from the central government to local governments and citizens; from the determination of national statutory holidays, to the declaration and review of intangible cultural heritage in various parts of the country, to local tourism The development of the project, the prosperous celebration of cultural festivals, etc., the traditional culture has become the "Xiang Yao" that all levels of government and enterprises compete for. The traditional culture of the Central Plains also experienced a dramatic fate from decline to booming.

Looking at these changes in the traditional culture of the Central Plains, although there are many reasons, this year's booming cultural landscape in the Central Plains region cannot but be said to be one of the important factors. The marriage between emerging culture and traditional culture has not only given Zhongyuan's traditional culture a chance to rejuvenate in the modern society, but has also brought inspiration to the development of emerging culture and become an indispensable and important cultural resource. The thickness and inclusiveness of Henan culture also provide possibilities for the integration of the new culture formats [2].

\section{The Content of Fusion}

Professor Yang Hanqing of the Henan Provincial Party School of the Chinese Communist Party believes: "The core essence of the outstanding traditional culture of the Central Plains is its positive and great national cultural spirit."[3] The Central Plains culture is ancient, long and mysterious. Since the Chinese entered the history of civilization, the Central Plains has long been in the country. The political, economic and cultural center of the Central Plains, with its distinct characteristics, reflects the history and cultural context of the Central Plains and conveys the folk culture awareness to the society in its unique form to enrich the lives of ordinary people. After the baptism of time, its cultural core has penetrated into various fields. The traditional culture of the Central Plains is the root culture of the Chinese nation. Every year, a large number of Chinese and overseas Chinese descendants return to the Central Plains to find their roots. This kind of cultural identity for the Central Plains culture has accumulated over a long period of time and accumulated to a certain degree. This has become a very emotional complex with emotional intensity. This is a bond for reunifying the Chinese nation.

The various ideological systems of the Central Plains culture, including Yi, Dao, Mo, Fa, Confucianism, Ming, Bing, and Buddhism, represent almost the major school of thought and theory in Chinese history. Its rich content is not only the essence of the Central Plains culture but also the Chinese nation. "Taking the Confucian culture as an example, the Confucian culture takes ethics as the core, emphasizing the moral responsibility of the individual towards the family, clan and the country, and regards safeguarding the country's overall interests as the most basic and most important value pursuit." [4] Some countries have their own homes. This simple patriotism strongly appeals to modern people to enhance their sense of cohesion, their overall vision and their dedication. The cultivation of the spirit of patriotism should be carried out as early as possible, and it can be embodied in emerging cultural scenes such as modern children's cartoons, nursery rhymes, and e-books. The stories can be based on the patriotic figures in the history of the Central Plains and the Confucian classics in the Central Plains. In order to create, at the same time, it is constructed in accordance with the records in the history books, and the patriotic propaganda is combined with the 
actual objects.

The traditional folk culture of the Central Plains is a kind of behavior, concept, form of organization, perception of life, and knowledge of the people. It continues in a simple folk form and freely expresses the love and praise of the Central Plains people for life and their pray for nature. The folk culture of the Central Plains comes from the people. Although it is very "grassroots," it is more appealing to people's original tastes and is more easily accepted and disseminated by the people. Through various activities such as the government's participation in the participation of the people, the official and unofficial links interact online and offline. Create a professional website to create the brand of Henan folk culture and increase its popularity. Offline, it is necessary to organize various non-governmental organizations such as folk local opera societies in Henan's major entertainment plazas. Through the public's listening, singing, and acting, the cultural maximum entertainment effect will be exerted, and then the activities will be enhanced through online and offline awards. It is also possible to organize folk art enthusiasts' associations in schools and colleges and universities to use the advantages of the school's localities and collect and organize local folk art through the guidance of professional teachers. University students can also use the fellowship committees to form teams based on different regions, collect and collect folk art works scattered in their hometowns during the holidays, and use these folk art works as the theme to combine the professional creation of folk literature as the subject of online literature, digital animation, and online magazines. , Toys DIY and other products, successful people can use this as a way to start their own business when they graduate. Pan Lusheng proposed: "Let intangible cultural heritage re-enter life, is the best protection for them." "Redesign and creativity, the traditional folk culture into a modern lifestyle, so that it is reborn.

\section{The Principle of Fusion}

The Central Plains region has long been China's political, economic, and cultural center. Folk art has also been able to develop rapidly. It has distinctive geographical features, such as Nanyang jade carving, Kaifeng embroidery, Zhu Xianzhen New Year paintings, Zhangzhou enamel, Luoyang Sancai, and Leiyang Mai. Stalk paintings, muddy maggots in Qixian, Mud monkeys in Huaiyang, etc. These rich folk arts are rich in ancestors' understanding and creativity of nature. Their original shapes, colors, and symbolic significance can all become important assets for the development of modern emerging culture. There are some famous tourist cities in the province, which combine the development of urban souvenirs with the promotion of traditional urban culture. Based on the local characteristics and traditional culture, combined with modern people's aesthetic interests, the company uses new media to develop handicrafts rich in local characteristics. Small household appliances, video games and other products have stimulated local tourism spending and inspired young people's enthusiasm for learning and developing traditional culture.

The key to the transformation of the traditional culture of the Central Plains in the emerging cultural industry lies in creative development and application. It should take "culture” as its source and "creativity" as the core, and use cultural exchanges as an opportunity to quickly find a market entry point for the cultural industry. The use of modern materials combined with digital modeling, printing and other automated intelligent control technology to enhance the product modeling and graphics, color quality, modern products full of traditional elements of the Central Plains to do more sophisticated, more time and the characteristics of the Central Plains, establish a new culture in the Central Plains Product brand image. The development of the emerging culture industry in Henan should be based on these rich traditional art contents. With the help of emerging technologies such as the Internet and new media, these traditional art forms will be presented in modern digital music, digital imaging, and network cultural products to meet modern consumers. The concept of consumption enriches the production methods and forms of cultural production and forms a new pattern of cultural communication [5].

"How to make Huaxia Civilization continue to innovate in its heritage and cultivate cultural brands with Central China style, Chinese characteristics, time characteristics, and international influence, continuously improve cultural soft power and enhance the cohesiveness of the Chinese 
nation, and become the current establishment of the Central Plains Economic Zone.”[6] The characteristics and diversity of the traditional culture of the Central Plains are the driving force for the continuous development of the cultural industry. The propaganda and development of the Central Plains traditional culture should establish its own cultural brand. The establishment of this brand should integrate the inherent goals of Henan's economic development with the existing cultural resources, deepen and integrate the traditional culture of the Central Plains, and promote the integration of science and technology and culture. The use of new technologies and new means enrich cultural production methods and forms of expression, the formation of a new pattern of cultural transmission. With the support of high-tech, digital, networking, and intelligent technologies have deeply affected the development of the cultural industry.

\section{Conclusion}

Through the above measures, the traditional cultural resources of Central Plains will be seamlessly integrated with the emerging cultural industries. Through the integration of the rich history, rich folk customs and outstanding ideology of the Central Plains region, the cultural creativity and market operation are effectively integrated with the emerging culture industry, so that the Central Plains cultural resources can be creatively developed and utilized. It will be an unprecedented and incomparable person. The cultural creativity is effectively integrated into the product development, brand image building and marketing of the Central Plains cultural industry, making the Central Plains culture visible, substantial, and audible. With cultural creativity, the Central Plains culture is endowed with the characteristics and soul to create creative development of the Central Plains cultural industry.

\section{Acknowledgements}

Fund Project: This article is the result of the research project of "Study on Li Zhi" (Study No.: SKL-2018-1241) conducted by the Research Group of Social Science of China and the Economic and Technical Cooperation of Henan Province.

\section{References}

[1] Wang Jian. The concept, classification and characteristics of emerging culture formats [J]. Chinese Urban Economy, 2011, (10): 92 - 97.

[2] Xiao Ronglian. The diversified development of emerging cultural formats and culture [J]. Academic exchanges, 2010, (3): 109 - 111.

[3] Yang Hanqing. The value of the traditional culture of the Central Plains in building a strong cultural province [J]. Learning Forum, 2005, (21): 7 - 9

[4] Pan Lusheng. Cultural seeds [J]. China Handyman, 2008, (2): 128 - 132.

[5] Liang Zhoumin. On the heritage and development of the traditional culture of the Central Plains [J]. Learning Forum, 2010, (26): 54 - 55 